\title{
A Cultural Ecological Frame for Mobility and Learning
}

\author{
Ben Bachmair and Norbert Pachler
}

\begin{abstract}
Mobile devices and services have achieved a level of critical mass and importance that requires us to take them seriously as new cultural resources. Mobile cultural resources emerge within what we call a «mobile complex), which consists of the interplay of structures, agency and cultural practices. These new cultural resources also can be considered to be valid learning resources which are (complex) because the components of the triangular structuration model, that governs them, interact with each other in intricate ways. They are in a state of perpetual flux, where boundary blurring takes place and where society and culture are experiencing the delimitation of mass communication. This paper is organized in four major parts:

The first part looks at trends of modernization, the mobile idelimitation of mass communication and learning. We consider mobility and learning to be key factors in this process of boundary blurring. A worrying global problem is highlighted, namely that schools are in danger of losing up to 20 to $25 \%$ of students who find it difficult to reach the defined curricular targets. This apparent rexclusions affects learners who set their own learning trajectories through informal learning mediated by mobile devices. We go on to argue that media, and user-generated contexts and content linked to them, are cultural resources.

The second part of the paper offers a preliminary discussion of the idea of learning and knowledge as resources in the transformation processes of learning inside and outside of educational institutions. Specifically, we examine epistemological challenges and propose a media ecological response to the delimitation of television and the mobile constellation of mass communication. This section looks briefly at existing conceptual frames, applying the concept of affordances originating from Gibson (1979). This leads us into a consideration of learning as appropriation or Bildung (formation).

In the third part of the paper we examine how the products of these transformation processes acquire the function of learning resources. Our discussion shows how the on-going process of individualization and fragmentation is enforced by the media of everyday life, which function as cultural objects, as symbolic material integral to users' personal life-worlds. Specifically, we make an analytical proposal about learning linked to a discussion of affordance and individualized, mobile, convergent mass communication.
\end{abstract}


Finally, in the fourth part of the paper, we examine educational practices of young people (potentially) rat risk within a cultural ecological frame in relation to the notion of user-generated contexts.

We conclude by pointing to recent work in the field, in particular Rymes' (2011) deference approach, which we consider to be relevant for the planning and evaluation of future mobile learning interventions.

\section{Trends of modernization, mobile «delimitations of mass communication and learning}

$21^{\text {st }}$ century Europe, like much of the rest of the world, is characterised by an increasing normalization of mobile devices and technologies - from mobile phones to tablets - in all spheres of life and for a wide range of purposes including communication, social networking, leisure and entertainment, personal organisation, shopping as well as learning in informal contexts. We take the view that mobile devices have achieved a level of critical mass and importance that requires us to take them seriously as new cultural resources and, by implication, as learning resources. Mobile cultural resources emerge within what we call a rmobile complexs, which consists of specific structures, agency and cultural practices (see Pachler, Bachmair and Cook 2010). These specific structures, agency and cultural practices of the mobile complex are in perpetual flux. From the conceptual perspective of «second modernitys and «reflexive modernity) (Beck and Grande 2010; Beck and Lau 2004; Beck, Bonss and Lau 2003; Lash, Giddens and Beck 1994), perpetual flux can be described with the term Entgrenzung (delimitation, boundary blurring), i. e. the removal of systemic demarcations. This boundary blurring or, in terms of Giddens' structuration theory, <delimitations is part of a new constellation of mass communication as well as of learning.

\section{Changing constellations of mass communication}

We consider mobility and learning to be key factors in this process of boundary blurring of mass communication, which became particularly visible with mobile phones and mp3 players, in particular Apple's iPod. At its inception, the mobile phone was simply a telephone that was independent from a landline. The iPod, starting in 2001, introduced completely new mobile features; it connected the mp3player with the Internet for music download through the software package iTunes. This opened up the music industry to the principle of individualized consumption on the go. It led to a normalization of individual decisions about music consumption through legal download at any time and from anywhere. Today, mobile phones tend to feature an mp3 player as standard and enlarge users' Internet options around streaming music. Well-known services at the time of writing are Spotify and Last.fm. Also, social network(ing) sites such as YouTube provided the option of 
uploading and viewing self-made digital videos. Alongside these developments, the diversification of mobile devices, from smartphones to tablets, made available a range of modes of representation from still images and writing, to videos and the spoken word.

As a consequence of these developments, multimodal mass communication has become the norm, but it is located within the domain of the individualized use of the Internet. The individualization of Internet use through mobile access via smartphone and tablets challenges the dominance of the Internet as a context defined by external providers. User-generated content not only dominates Internet television (cf. YouTube) but also users create specific patterns and contexts of mobile use in relation to their own (perceived) needs. Individuals construct their own specific media contexts on the go, within - and in response to - the specific contexts of their everyday lives as well as in relation to the Internet.

This ubiquitous, individualized use of mobile devices within a convergent media system has started to determine mass communication. Of course, there are obstacles such as expensive flat rates or a lack of connectivity. But ubiquity as a category that combines individuality, convergence and mobility, has started to define a new constellation of mass communication. The practical dimension of ubiquity means that a user of a smartphone or of a tablet has at his or her disposal downloads and uploads at any time and from anywhere. This leads to a fragmentation of contexts, but these fragmented contexts are generated within the dominant sites of users' activity patterns and self-selected Internet sites.

\section{Changing constellations of learning}

The phenomena of a new constellation of mass communication with individualized mobility and user-generated contexts (Bachmair and Pachler, forthcoming) indicate an enormous paradigm shift. Parallel to this on-going boundary blurring in mass communication, learning is in a process of transition. The growing importance of learning in informal contexts and across the life course is symptomatic. Schools, and their approaches to teaching and learning, depending on one's vantage point, are stable or resistant to change. However, dominant global economic changes require schools to rethink their approaches. PISA, the Programme for International Student Assessment, and governments around the world striving for global knowledge societies and creative economies are drivers for education systems to <modernizes by adopting the rationale of output-orientated knowledge production. Assessment systems such as PISA are, therefore, part of the transformation of schools for the purpose of strategic knowledge production. Standardized assessment is used as a driver to deliver objectified judgements concerning learning outcomes and to serve as a measure of success in aligning teaching and learning processes to predefined curricular targets. Along with other 
drivers in this modernization process, mobile devices have been, and continue to be, excluded from the cultural practices of the school. However, tablets, which operate within the logic of computers, are increasingly viewed as promising to ¿deliver output-orientated learning and a growing number of schools have started to purchase them (see e.g. http://larrycuban.wordpress.com/2013/06/21/ipads-inlos-angeles-and-tco/). This means mobile devices are becoming institutionalised resources for fulfilling strategic learning standards and goals.

Lauder et al. (2006, 719-849) describe this neoliberal transformation as assessmentapproach and view it as a reaction to, and as part of the on-going societal transformation of globalization, which transfers basic principles of a controlled and output-orientated production to education and learning. In line with this outputorientated knowledge production paradigm, personal competences are defined as learning outcomes. Also, media education has followed this trend of knowledge «technologys by targeting media literacy (Medienkompetenz), which transfers the capability of media use in an increasingly open media market to the individual user as part of their personal potential for agency.

With the trend towards output-orientated knowledge production in many countries, schools are in danger of losing up to 20 to $25 \%$ of young people who find it difficult to reach the defined curricular targets. They tend to belong to socio-cultural milieus, which are at a distance to school and formal education. Of course, there are different reasons, linked to migration, low family income and the gender gap. These young people are at a distance to formal education and are disconnected from formal learning in school. After completing compulsory education they tend to face difficulties when trying to access training, further education or employment. But for this group, often referred to as NEETs (McCrone et al. 2013), the concept of competencies as individually generated and individually accounted for capability loses its validity, because they act outside of the education system. In this way, the school as an institution is increasingly losing its legitimatised power over learning for all citizens. A «modernization〉 programme for schools driven by the assessment of attainment and competencies, therefore, appears to come at a price, namely that of seemingly excluding a significant number of young people from institutionalised learning. This exclusion affects learners who set their own learning trajectories through informal learning mediated by mobile devices and services through their life-course. At this point «modernizations re-enforces the boundaries of schools and of traditional definitions of learning and leads to the exclusion of specific learning resources, including that of mobile devices, as they are viewed as existing within an entertainment paradigm. The exclusion does not happen only through the social exclusion of learners, it also excludes learnerdefined and learner-generated resources. 


\section{Resources for the knowledge society}

A second dynamic of modernization is that it tries to overcome the learning routines of schools. It results from the motivation of addressing the deficits of teacher-guided instruction with its framing of learning as memorization and repetition of isolated chunks of knowledge. One modernization target is to ensure the fitness-for-purpose of the school for the knowledge society with a so-called «war for talents» (Brown and Lauder 2006, 130) which can be viewed as a kind of «digital Taylorism» (Brown and Lauder 2006, 127). «Digital Taylorism» seeks to achieve efficiency gains inter alia through standardizing assessment in order to be able to better rank learning outcomes. However, it also seeks to integrate educational concepts which pursue seemingly antithetical forms of learning such as learner autonomy characteristic of situated learning (Lave and Wenger 1991). Modernization in the sense of «digital Taylorism» correlates with neoliberal ideas, which, for example, transfer risks to individuals, and makes them responsible for success or failure. An anthropologically and historically aware perspective on teaching and learning, one that identifies the humanistic values of schooling and education, is in opposition to «digital Taylorism?.

Another perspective, which we find appealing, is social semiotics (see Kress 2010), which understands learning as an important form of meaning making in a multimodal world characterised by provisionality. In this line of argumentation, the issue of learning resources comes to the fore and with it the question of the role of mobile mass communication and associated mobile devices as optional resources for learning.

The issue of mobile devices as learning resources is not necessarily linked to a neoliberal modernization programme such as digital Taylorism. In a critical vein, Lehner $(2010,272)$ emphasizes «knowledge as a central economic resource» for society. Knowledge as a resource has become an «independent factor of production», which is entangled with inequality. Furthermore, the rapid development of knowledge and its segregation produces insecurity, which makes knowledge a risk factor (Lehner 2010, 273). These conceptualisations are reflected in the international educational discourse about learning, in particular in «situated learning" (Lave and Wenger 1991) and "collaborative knowledge building» (Scardamalia and Bereiter 1999). From these perspectives, media as well as usergenerated contexts and content are cultural resources. And, the issue of resources has to be considered educationally in the tradition of the critical discussion of energy and nature as not simply available for exploitation. Media, as well as new user-generated contexts and content as cultural resources, have to be viewed from a perspective of a cultural ecology. 
In a wider consideration we interpret this development with reference to Bourdieu as «social capital» (e.g. Bourdieu 1986), which provides the scope for dealing with social differences in learning success or failure. Within his notion of cultural capital, Bourdieu constructs three sub-categories: ‘objectified) capital, such as artworks, which can be literally bought and sold; sembodied capital, in the form of habits and dispositions of a person, such as knowing how to behave at the opera or how to view a painting at an exhibition; and institutionaliseds capital, in the form of academic qualifications and recognised professional credentials (Legg 2012, 159). In relation to individualized, convergent, mobile mass communication the objectified cultural capital can be the expensive iPhone or the clicks on a video on YouTube; the embodied cultural capital, e.g. how to use Facebook with peers or find videos for a school subject on YouTube. Institutionalised cultural capital can be the recognition of informal learning within media contexts by the school or within vocational training.

\section{Epistemological challenges - a media ecological response to the delimitation of television and the mobile constellation of mass communication}

At this point in our discussion of the transformation of mass communication and learning with reference to the concept of resources, we reach the crucial point of an ecological interpretation of societal developments. Knowledge and learning are resources, along with the actual mobile devices that have become integral to everyday life in the context of the individualization of mass communication. By proposing an ecological view of mobile devices, and the artefacts accessed through and produced with them, we align our discussion with the comparable processes of transformation in thinking about energy and nature from the 1970s onwards. From an ecological perspective, and with reference to the exploitation of nature, two political issues arose, namely inequality and power in the provision of food and the use of energy. In the field of culture, attempting an ecological interpretation of the changing nature of mass communication and learning in the context of the rise of individualized, mobile, convergent mass communication and its devices and services, the focus turns to cultural resources within human development in relation to school and media education. At one level, cultural resources are individualized mobile devices within media convergence such as smartphones, mp3 players, game consoles or tablets in the context of social media such as YouTube and Facebook. Also, knowledge in all its specifications of products and process, such as informal learning, competencies, literacy etc., is covered by the concept of cultural resource.

Because our argument is located in the field of learning with media, technologyenhanced learning, and media education, we want to look briefly at existing conceptual frames, among them the media ecology of Postman $(1983,1993)$ 
in the U.S. and that of Baacke (1989) in Germany. Both offer restricted system approaches, which do not respond to the on-going processes of boundarycrossing modernization. Alternatively, we try to apply the concept of «affordance» that originates from Gibson (1979). This concept derives from an anthropological view of perception as a contextualized activity and can be widened culturally by a discussion of contexts provided by mass communication and education. Such a view opens the scope of our argument to the interrelationship of new mobile, individualized, convergent constellations of mass communication and learning. As basic frame for learning we refer to appropriation as Bildung (formation), the German concept of the late Enlightenment of the 1790s (Humboldt 2002), which combined Rousseau's anthropologic concept of learning as personal development with the cultural frame of learning as development resulting from internalizing cultural products. The dynamic for human development of Bildung comes from formative expression triggered by the appropriation of cultural products. The curricular model is based on the selection and delivery of relevant cultural objects for appropriation by learners. This idea was actualized among others in the field of Cultural Studies in relation to media use as a cultural activity (see Pachler, Cook and Bachmair 2010).

\section{Postman's system approach and mono-dimensional proposal for practice}

Explicit approaches to media ecology such as those by Postman (1982) or Baacke (1989) emerged as a response to the changes brought about by television which had amalgamated with everyday life. Both endeavours work with a systems approach to describe the interrelationship of everyday life and television as the dominant mass medium. Postman discusses the systems of childhood and television as cultural constructs. The cultural invention of the medium television changes the public sphere, which has a deep impact on childhood. In particular, television makes public aspects of the secret adult world, which had tended to be unavailable and not accessible to children since the invention of movable type printing as they lacked the requisite literacy skills. But Postman considers certain «secrets〉 to be essential for childhood. Postman's simplistic claim is to switch off television in order to protect childhood. In Amusing ourselves to death Postman advances the view that inherent in a particular medium is a specific way of dealing with information and he discusses the differences between oral, literate and televisual cultures, arguing that the latter fosters a passive mentality by dissolving the traditional relationship between information and action. Postman's practical proposal is to conserve the pre-television media. This proposal for media educational practice is more or less the moral romanticisation of the traditional, without a discussion of gains and losses, or of accounting for dominance and exclusion. Calls for «switching off the modernization processes are not at all unusual for the ecology of the 1970s 
and 1980s, as is evident for example in the refusal of products of an industrialized agriculture by some people who instead preferred to knit home-produced wool. Postman's answer to the blurring of boundaries in the public sphere was, and is, inadequate as a response to the complexity of cultural development processes, such as the boundary blurring of mass communication. It remains within the monodimensional rationale of the industrialization of communication, which Horkheimer and Adorno (1969) criticized through their dialectic analysis of the culture industry of the 1940s.

\section{Baacke's system approach to media in the life world and human development}

In the Federal Republic of Germany, Baacke promoted media education for television as part of viewers' life worlds, which led to a social ecology that avoided the conservative certainties and the moralizing tones inherent in Postman's approach. The basic idea revolved around the life world as the system in which people and media are related to each other. Baacke had already raised the question of the relationship between communication and action in the context of mass communication in 1973, when he discussed communication and competences as a frame for media education.

In this system approach, mass communication of public media (newspaper, radio and television) provides a general frame for communication in society (Baacke 1973, 180-1). Baacke contributed to the view in media education of people as active media users who develop competencies through participation in mass communication. His question about the person as actor focused on linguistic and communicative competence (p. 257) of the people in the system of mass communication and also on the use of language in their life worlds. In this discussion of language and life $(1973,257)$ the concept of ecology appears.

In 1989, with his later research on media socialization, Baacke's system view on media in the life worlds of children and adolescents took a practical turn when he investigated the media world of young people in different spheres. He was particularly interested in the developmental processes of young people, how they gradually disengaged from their families by seeking friendships with peers, in pairs or cliques outside of home. Baacke accompanied young people on their journeys through the world of media that was «located in dreams, desires, thoughts and fantasies». These inner and outer media spaces are part of the social ecology young people inhabit (ibid., 95).

In his later work, Baacke (1999) linked the development of children and young people to the concept of inner and outer media spaces and the concept of zones of development. He distinguished four zones, ranging from the ecologic centre of the family at home, to ecological spaces such as neighbourhoods, to places such as kindergartens and schools, and the ecological periphery such as tourist resorts. 
These socio-ecological zones combine the internal and external media worlds of children and young people to a structured system. Media ecology investigates this system of the inner and outer media world. For an overview of the media ecology of Dieter Baacke see: Ganguin 2008; Ganguin and Sander 2005.

Postman's and Baacke's media-related systems are directed, albeit to different degrees, towards the development of children and adolescents. They describe and evaluate differently the relationship of children and adolescents to media as part of world systems. This relationship remains conceptually rather vague. Postman laments the intrusion of media and their structures in a childhood that is in decline. Similarly, Baacke, in his media-ecological investigation in 1989, features the culturally critical statement: "young people in the maelstrom of the media». In his practical work, however, Baacke $(1989,11)$ proposes to teachers not to demonize the modern media but to «accept them as given and unchangeable». But, he posits, "we should live not only in media worlds» $(1989,11)$.

One could ask how Baacke's system approach is able to evaluate media worlds and human development by refusing media as a cultural invasion on the one hand, and on the other to accept them but only under certain conditions. This ambivalence prevents it from addressing independence as a salient structure of the cultural ecological system. At this point the concept of affordance is helpful, which stems from perceptual psychology. We use the concept of affordance to view media as part of a contextual system with the perceiving subject at its centre.

\section{The concept of affordance and a context-related media ecology}

Gibson (1979) offered a kind of anthropologic anchor to an ecologic argumentation by focusing on perception. Perception takes place in the interdependent relation of perceiver, object of perception and environment. Gibson's focus on perception introduces a relational understanding through the category of affordance. This relational understanding augments the educational focus of Baacke's system approach of the inner and outer world with the concept of affordance aiming to address the contextual relationship of the perceiver and object.

Originally Gibson $(1979,63)$ introduced the concept of perception in opposition to the stimulus-response scheme:

The ambient stimulus information available in the sea of energy around us ... is not transmitted, does not consist of signals, and does not entail a sender and receiver. The environment does not communicate with the observers who inhabit it. Why should the world speak to us?

The theoretical model of stimulus and response is not of interest here. But Gibson's attempt to deal with the contexts of perception as the centre of an ecological system-theoretical analysis is very interesting: 
The affordances of the environment ... are in a sense objective, real and physical. ... An affordance is neither an objective property nor a subjective property; or it is both if you like. An affordance cuts across the dichotomy of subjective-objective and helps us to understand its inadequacy. It is equally a fact of the environment and a fact of behaviour. It is both physical and psychical, yet, neither. An affordance points both ways, to the environment and to the observer. $(1979,129)$

The British learning technologist Oliver (2005) applies Gibson's ecology of perception to media and design phenomena. With reference to current media technology and media design, he characterises affordance as «mapping», "cultural constraints» and «conventions» (ibid., 406). He expands this line of argument and considers all cultural artefacts as cultural text (ibid., 411). It is necessary to set up a critical discourse to identify and evaluate the affordance of cultural texts. This argumentation opens the anthropological relational model of perception to culture. Oliver interprets the perceived objects as cultural artefacts, which work as culturally designed texts (ibid., 411). The interrelation of perceiver, object and environment does not just include designed text. Furthermore, the environment is a culturally designed text that works as context by featuring structures and agency of perceptions. In this line of argumentation, context becomes a defining feature of a cultural ecology.

From the perspective of a cultural ecology with a focus on perception, the question arises how elements of the perception system, namely the perceiving subjects and the perceivable environment, relate to each other. At a theoretical level, Gibson posited a relationship of reciprocity between perception and the perceptible through the concept of affordance. Affordance is a correspondence of subject, perception and objects in and across contexts. Gibson and Pick (2000, $14 \mathrm{ff}$.) explained the rather artificial term saffordances with the example of a chair that is designed to be sat on. This example is naive, because, as we know, children use chairs to play with and not only for sitting on them. That means that the affordance, the relationship of the chair and the child, is culturally constructed by the respective social and cultural environment and not per se given. For the perception of media as cultural products it is clear that media reception is part of a complex process of selection and processing, which corresponds to what is semiotically objectified in a media text. Applied to the Internet, it is about the relationship between text and contexts with the acting subjects, who are involved in diverse contexts such as school or peers. Involvement means that the acting subjects generate new contexts, for example, by combining different contexts on the Internet with different social groups and activities of everyday life. In mass communication, now characterised by boundary crossing, the mobile phone provides access to contexts by virtue of text production and text reception. Different mobile devices offer or challenge different affordances within and beyond contexts. 


\section{Affordance and the individualized, mobile, convergent constellation of mass communication and learning: an analytical proposal}

We began our outline of an ecological approach with trends of boundary blurring in mass communication with particular reference to mobility, individualization and convergence. We then offered a preliminary discussion of the idea of learning and knowledge as resources in the transformation processes of learning inside and outside of educational institutions. In this section we ask the question how the products of these transformation processes acquire the function of learning resources. The answer, among other things, relates to the notion of mobile devices as cultural resources: the on-going process of individualization and fragmentation is enforced by the media of everyday life, which function as cultural objects, as symbolic material integral to users' personal life-worlds.

The interrelationship of structures, agency and cultural practices

We view the role of affordance as a productive interrelationship of elements of the social capital of learners in the contexts within which they are generated and as entangled interpretations of, and activities undertaken by means of mobile offerings, specifically smartphones. Affordance is realized in the processes of meaning making. In our definition we view meaning making as generative. The processes relating to affordance can be analyzed by means of a triangular model, which draws on Giddens' structuration model (1984; Pachler, Bachmair and Cook 2010, $25 \mathrm{ff}$.). We are interested in the structures, the agency and the cultural practices of the mobile, individualized, convergent constellations of mass communication and the attendant transformations of learning. We summarize this development as «mobile complex and as «learning complex». Our triangular structuration model organizes analysis around the following three nodes:

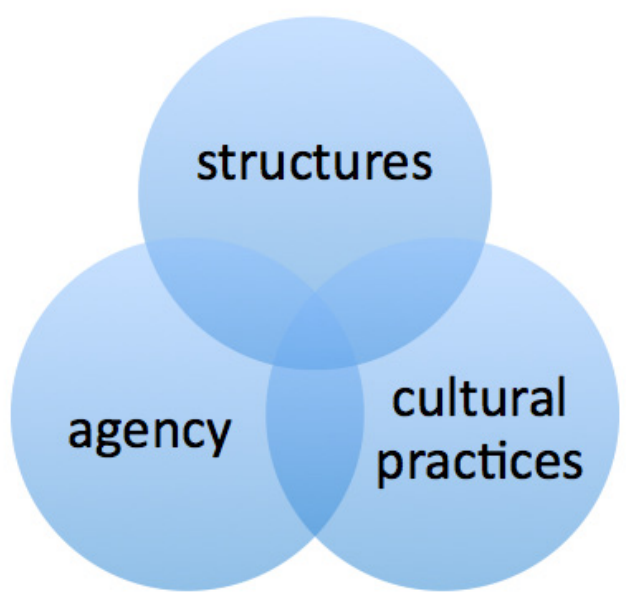

- technological and sociocultural structures of the mobile complex and the learning complex;

- agency of users; and

- cultural practices of media use and learning. 
It targets the cultural capital within which users appropriate cultural resources for their personal development within the wider frame of the mobile complex (see also Pachler, Cook and Bachmair, 2010).

In the foreground of the technological and socio-cultural structures outlined briefly above are changes to mass communication, in particular mobility, individualization and convergence. One outcome is that just a part of mass communication still operates in a linear way. That means, only some media are still produced professionally for mainly passive mass audiences. With social media, which Internet users increasingly access via their smartphones, media content is produced within individualized contextual frames (user-generated content and contexts) by users. Generating content and contexts has become a routine practice worldwide.

Despite this normalization, the generation of contexts continues to be conceptually and educationally little understood (see also Pachler, Cook and Bachmair 2010).

Referring partly to Dourish (2004), we view context as a frame under construction for optional combinations of actions, representational resources inclusive of media and literacy, virtual and local sites or social sites such as socio-cultural milieus. These cultural practices in mass communication are largely in juxtaposition to institutional teaching practices where instruction follows more or less a teacher-guided transfer model. The affordance of mobile devices as interrelated options for education can succeed when the traditional, linear model of teaching is extended, at least temporarily, with episodes of situated learning. (see e. g. Bachmair et al. 2011)

A significant feature of a change in agency is the neoliberal transformation of the learner into an entrepreneurial self («unternehmerisches Selbst»; Bröckling 2007) responsible for his/her own resources and the development of these resources in order to acquire the relevant knowledge, skills and understanding and to develop the necessary personal capacity for learning to achieve self-optimisation. Autonomy and responsibility for personal success are general principles of subjectivity in a socially divided society (see Butterwegge et al. 2008, $167 \mathrm{ff}$.). This correlates with the habitus of target-orientated activities and learning. But in mass communication other forms of habitus are dominant such as self-representation and play. With a mobile in one's hand linked to social network(ing) sites, selfrepresentation and play are standard practices. Institutionalised learning, however, is still dominated by target orientation. On the other hand, agency in the context of social media usually operates at a low level of reflexivity; chattiness and banality are in the foreground of mass communication. However, the school could assimilate banal chatter because of its links with learning informally in everyday life. Of course, part of the assimilation strategy is to graft reflexive and traditional forms of communication onto the use of mobile devices. Our work with at-risk learners suggests that mobile portfolios offer similar new forms of reflexivity (see e. g. Bachmair and Pachler 2013). 
The cultural practices of learning and media use can be related to each other, if they support target-orientated knowledge transfer and knowledge accumulation. But there is a divide between mass communication and learning in informal contexts outside the school, and teacher-guided and assessed instruction inside school. As already mentioned, the linear model of school education is under pressure from the on-going process of cultural transformation. At the time of writing this pressure can be seen to lead to educational policy initiatives seeking the optimization of knowledge output. In this logic, there is a correlation with tablets conceived as mini-computers. However, there is also an alternative view, which we see ourselves contributing to, promoting new modes of learning within technology-mediated learning environments characterised among other things by user-generated contexts.

\section{Tools to make ecological complexity operational}

We propose tools for the analysis of mobile learning, which we call parameters, and focal points for planning.

\section{Didactic parameters for analysing and planning}

The following four didactic parameters create a didactic space for teaching and learning (see Pachler, Bachmair and Cook 2010, $209 \mathrm{ff}$.). They provide a map of possible approaches to assimilating cultural resources into school. The agents of this assimilation are mainly teachers and their emphases and preferences along the four didactic parameters. The four parameters span the poles «static and «flexible». They link opposing learning and media practices and address differences in learning habitus. If one applies these four parameters within the global space of learners' life-worlds, the scope and variability for analysing and planning learning situations and context becomes considerable.

Parameter A: Learning sets

Pole: Practice of the school --- Pole: Practices of mobile devices

The concept of a learning set comprises all possible arrangements of constituent variables of learning such as teacher, learner, environment, media/tools, curriculum etc. This includes, for example, teacher-centred input in a lesson, homework tasks completed with a laptop or an Internet community for Maths, etc. The dimension of a learning set across the poles of school practices and mobile device practices captures the possibilities for students from school-based work to learning informally in everyday life contexts as well as in-between. Everyday life includes the use of mobile media for personal use and, of course, for meaning making in different contexts, for intentional and planned or serendipitous and accidental learning. 
Parameter B: Relationship to the object of learning

Pole: Mimetic reproduction --- Pole: Personal reconstruction

One desirable characteristic of successful instruction is to facilitate a type of learning, which does not focus only on the passive repetition and memorization of learning objects. Collaborative knowledge building is one widely accepted and practically used alternative. Examples of mobile homework on YouTube offer specific and workable suggestions about how to work with these mobile, convergent practices in the school (see e.g. Pachler, Bachmair and Cook 2010, 293-6). Collaborative knowledge building can combine mimetic practices of learning with media use for personal reconstruction. One important task of schools is to move (native), reconstructive learning onto a higher level of reflexivity.

Parameter C: Institutional emphasis on expertise

Pole: School curriculum --- Pole: Personal expertise

There are a number of teaching and learning models («scripts); see Kollar and Fischer 2008), which contain a variety of options for relating the personal expertise of students to a given school curriculum, thereby opening up socio-culturally relevant directions for teachers such as collaborative knowledge building, teacherguided instruction or situated learning.

Parameter D: Modes of representation

Pole: Discrete (mono media, mono modal) --- Pole: Convergent

Mobile media, in particular the mobile phone, have become part of everyday life because they have affordances in relation to multimodal representation and enable near-ubiquitous access to convergent media for which the Internet is the global network. Mobile media offer the following applications for learning:

- interaction with peers by telephone, messaging, email;

- picture and video recording;

- storage of photos, data files, games, software etc.;

- access to the media world, Internet, archives (media convergence);

- individual disposal of time and space through the formation of contexts and situations;

- multimodal representation. 


\section{Focal points for planning mobile learning}

The focal points represent the educational and didactic options within the four parameters in the form of guidelines and combine them with the breadth of available mobile applications.

a. To integrate informal learning in formal learning contexts

Mobile devices as part of everyday life offer the possibility to integrate learning in informal contexts and knowledge of everyday life in the school. They function as an interface between the culture of children and young people, their everyday life and learning in the classroom.

b. Setting up episodes of situated learning

Mobile devices support forms of situated learning. One basic form is to integrate episodes of situated learning into teacher-guided instruction. Metaphorically speaking, teacher-guided instruction functions like a learning path, which opens to squares of situated learning by means of mobile devices.

c. Generating learning and media contexts

Mobile devices contain the option for learners to generate their own contexts of learning. These learning contexts arise as interfaces of media convergence with the Internet, entertainment offers of media, the learners' life worlds and the school.

d. Mobile devices serve as conversational threads

In the convergent world of media and the Internet, mobile devices function as bridges between user-generated contexts and school. They are part of conversational threads between everyday life and convergent media.

e. Supporting students as naïve experts, e.g. of media use in everyday life within the school

In the process of individualization and fragmentation of our society students, like anyone else, are naïve experts in everyday life. Ubiquitous mobile devices function as tools of everyday life with play having an important role.

f. Setting up responsive contexts for personal development and learning

We view learning as an integral part of personal development, which takes place in supportive contexts responsive to learners' actual and key development needs. Contexts generated by children and young people in the mobile, individualized, convergent media world are usually closely related to the issues and topics of their personal development. Learning succeeds if these developmental topics are part of learning. One may not expect that this is accomplished without detours. 


\section{Educational practices around user-generated contexts with at-risk learners within a cultural ecological frame}

The notion of affordance suggests an orientation towards contexts, which support learning as an integral part of learners' personal development as proposed by the sixth focal point above. The following scenario was designed as a presessional learning opportunity for learners about to embark on a media course after compulsory schooling. The intention was to give participants the opportunity to gain a new and positive understanding of learning in the context of formal education. The key success criterion for such an understanding was considered to be the ability to view learning in a formal educational setting as resonating with experiences of learning in the informal contexts of participants' everyday life worlds. The mechanism by which to achieve this was the mobile phone, which we consider to be a cultural resource normalized in the everyday life of young people. By means of the mobile phone, participants were encouraged to bring elements of their learning in informal contexts into formal educational contexts.

The workshop was the scoping for an induction to a media design course for newcomers to the college and ran over two days. It started with an open, associative investigation of the college as learning environment. Participants were invited to use their own mobile phone or smartphone for taking photos about their exploration of the college. The intention behind using the personal mobile phone or smartphone with the photo application was for participants to link their everyday life outside the school with their activities inside the college. Participants should not only become familiar with the college, they should also have the opportunity to connect their everyday life with its specific learning options with the college. The idea was for the personal mobile device, conceptualised as a key cultural resource of participants, to function as a link between two contexts, which are usually alienated by the rules and regulations of educational institutions. Because the workshop was linked to a media course, participants were invited to process their photos by means of new presentation software, Prezi. They were also given the opportunity to have one image printed on a t-shirt. Because the photo activity was intended to link the context of the college with the context of everyday life the facilitator invited participants to bring photos from home; home represented the personal sphere of everyday life.

Whilst working on their Prezi presentation, participants selected one image, a photo taken during the investigation of the college or which they brought in from home. It was up to participants to decide which image they printed on their t-shirt. At the end of the two day workshop, participants gathered as a group all with their workshop t-shirts but each with a different images on it. Participants liked this very much, because the t-shirts visualized and represented their personal identity within the social unit of the new group. But they retained individualism by means of the 
different images. The way in which participants positioned themselves in relation to the new college environment became partly visible. The still lifes of the photo excursion through the college (see Figure 1 below) contained subtle messages of participants to the college, among other things, that they see the college as an artificial site. Thirdly, the intention was for specific resources in the participants' personal contexts to become visible, especially for the facilitator.

At one level, different images can be read as portraying differences in individuals. These differences are an expression of a variety of contexts, resources in contexts and access points to contexts which are important because they are part of participants' individual learning habitus.

The photos depicted on the t-shirts portray the college from the perspective of young artists and afford us certain insights about the participants as individuals and as learners in relation to media design. They portray participants as being professionally-orientated and as possessing experts, not novices or outsiders.
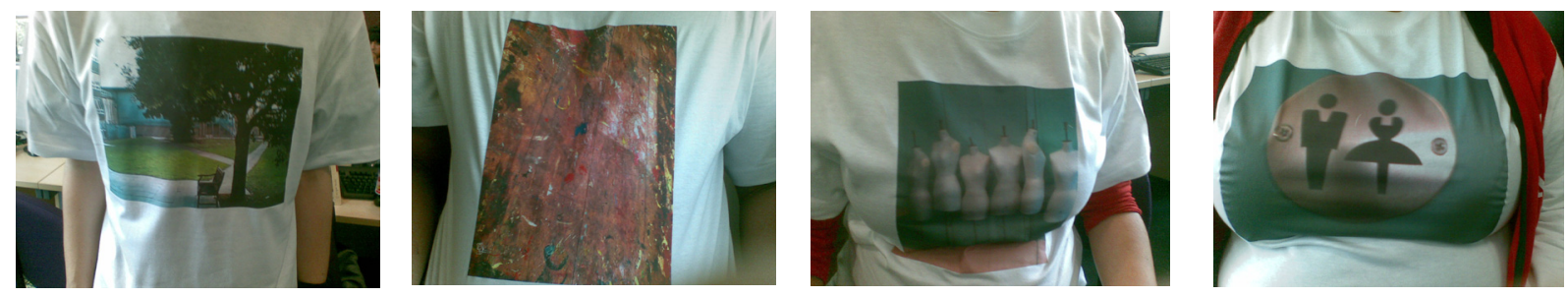

Figures 1: Images of the school in the style of artistic still lifes: a calm garden environment with a bench and a tree; details from the floor from the art studio; mannequins from the fashion department; toilet sign

In addition, the images convey messages about context relationships of high relevance to the facilitator, namely interest in media design. This implies that the focus need not be on extrinsic motivation, but instead on the provision of professional equipment relevant to Internet design and to social media within a professional context of fine arts and design. Participants would seem to expect, albeit at a low level of awareness, a context for design and communication with media practitioners which the college needs to take seriously.

The t-shirts represent different themes, some of them closer than others to the college as a formal learning context. Two types of images refer to the formal media curriculum. For example one young woman shows herself as a Manga specialist and specialist in entertainment media. The t-shirt image displays the faces of the two protagonists of a manga cartoon for young people, $L$ vs. Kira. By making this choice, the participant refers to the media design focus of her course but with clear reference to media and design styles outside of college. Some participants refer with their t-shirt images to the Internet and social media. One participant presents himself as a dancer by using a photo from his Facebook site. Another, a young 
woman, wears the well-designed characters MEHR on her t-shirt. Yet another opts for a stylish and also well-designed combination of faces and characters. One young man chooses a photo of a fashion model. The message is about perfection in the use of the Internet and a good understanding world of design.

Rather distant to the college's learning context are images which show their own home, their family and peers. One t-shirt features photos about friends. The style is that of a photo album. The young woman who wears this image on her t-shirt is probably looking for a familiar context with peers within the college environment. A foreign national flag on a t-shirt opens the context to politics and national identity. A young man features his national colour on his t-shirt; perhaps it denotes being politically aware as a migrant.

Each t-shirt image opens a personal context such as the Internet or the home. Some of these contexts are in greater proximity to the media course, for example, the media images compared to the national colours. All images provide an opportunity for understanding the personal development of the bearer. All t-shirts together comprise and embrace a small cosmos of diversity but with several streams, including the baseline of the course, media expertise.

The question arises how to deal with the diversity of the course-related contexts, which are depicted by the t-shirt images. Our proposal is to find an educational and didactic response in relation to the issue of social justice (see Bertelsmann Stiftung, Institut für Schulentwicklung 2012, 17-21, 25-36).

The educational fine-tuning required for making formal educational opportunities relevant relates to scaffolding of developmentally-orientated learning, which is one of the design features of the t-shirt example. Another element is the recognition of the expertise of students, as photographers or as manga experts of youth culture. Such an expertise is a cultural resource, which is not in the foreground of the curriculum. But from the perspective of the curriculum, a teacher - as agent of the institution school - has the option, increasingly even an obligation, to recognise such non-curricular competencies of learners. This issue of cultural resources was discussed in Review of Research in Education 35(1) under the heading of cultural resources in the process of globalization. Wortham's (2011) focus is on the recognition of youth culture within the processes of globalization and migration: "globalization has transformed youth cultures, bringing resources from around the world into practices that are nonetheless tied to local cultures, histories, and material constraints» (ibid., ix). That means in practice that schools need to «appreciate the full complexity of youth practices - not just their heterogeneity and rapid emergence but also their reflexivity» (ibid., viii). Rymes (2011) stresses the potential of resources of youth culture because "they encapsulate shared experience and deference to complex, collective social understanding» (ibid., 208). From this perspective, and on the basis of published research, Rymes identifies 
two relevant curricular strategies to deal with the resources of youth culture in school, the «deference approach» and the «denial approach». The denial approach corresponds with critical literacy. Teachers motivate students to deal critically with mass media in order to achieve their own means of constructing meaningful media texts. The deference approach targets the assimilation of cultural resources of young people into teaching and learning. The recognition of global youth culture and associated linguistic and discourse habits as legitimate resources for learning is a prerequisite. Our intention is to utilise Rymes' deference approach for the planning and evaluation of future mobile learning interventions.

\section{Summary}

Our line of argumentation started with the «mobiles delimitation of mass communication as a structural feature of ongoing modernization that corresponds with a changing constellation for learning. With reference to the widely used notion of a ‘global knowledge society` we considered learning processes, learners' capacities and learning outcomes as well the new mobile devices of mass communication as cultural resources. Through this, we dealt both with the ideological perspective of neoliberalism, which views resources in terms of exploitation, as well an opposing ecological view, which we linked to culture. With reference to existing theoretical endeavors in the fields of media and ecology, we drew on Gibson's (1979) ecology of perception and applied his concept of affordance to the new individualized mobility of mass communication and learning. A triangular structuration model with its feature elements of agency, structures and cultural practices served as hermeneutical tool for describing and analysing the affordances of mobile devices, in particular media convergence in the context of social networking and teaching and learning as a set of conversational processes. In this context we considered the pedagogical task of operationalizing the use of mobile devices for teaching and learning with particular reference to planning and evaluation. For this purpose we proposed four parameters as well as six focal points for planning of scenarios for mobile learning. Finally, we provided an example context-aware learning. The example, in which mobile devices supported the investigation of a college as a learning environment, discussed the affordance of mobile devices in formal and informal learning contexts combined with representational means such as social networking sites.

\section{References}

Baacke, Dieter. 1973. Kommunikation und Kompetenz. Grundlegung einer Didaktik der Kommunikation und ihrer Medien. München: Juventa.

Baacke, Dieter. 1999. Die 6-12jährigen - Einführung in die Probleme des Kindesalters. Weinheim, Basel: Beltz. 
Baacke, Dieter, Günter Frank, Martin Radde and Manfred Schnittke. 1989. Jugendliche im Sog der Medien: Medienwelten Jugendlicher und Gesellschaft. Opladen: Leske+Budrich.

Bachmair, Ben and Norbert Pachler. Forthcoming. «Framing ubiquitous mobility educationally: Mobile devices and context-aware learning.» In Seamless Learning in the Age of Mobile Connectivity, ed. Lung-Hsiang Wong, Marcelo Milrad and Marcus Specht. New York: Springer.

Bachmair, Ben and Norbert Pachler. 2013. "Composition and appropriation in a culture characterised by provisionality.» In Multimodality and Social Semiosis: Communication, meaning-making and learning in the work of Gunther Kress, ed. Margit Böck and Norbert Pachler, 211-220. New York: Routledge.

Bachmair, Ben, Maren Risch, Katja Friedrich and Katja Mayer. 2011. «Eckpunkte einer Didaktik des mobile Lernens - Operationalisierung im Rahmen eines Schulversuchs.» MedienPädagogik 19 (11. März): 1-38. www.medienpaed. com/19/\#bachmair1103.

Beck, Ulrich and Edgar Grande. 2010. «Varieties of second varieties of second modernity: the cosmopolitan turn in social and political theory and research.» The British Journal of Sociology 61 (3): 409-443.

Beck, Ulrich and Christoph Lau, ed. 2004. Entgrenzung und Entscheidung: Was ist neu an der Theorie reflexiver Modernisierung? Frankfurt: Suhrkamp.

Beck, Ulrich, Wolfgang Bonß and Christoph Lau. 2003. "The theory of reflexive modernization: Problematic, hypotheses and research programme, Theory.» Culture \& Society 20 (2): 1-33.

Bertelsmann Stiftung Institut für Schulentwicklung, ed. 2012. Chancenspiegel. Zur Chancengerechtigkeit und Leistungsfähigkeit der deutschen Schulsysteme. Gütersloh: Verlag Bertelsmann Stiftung.

Bourdieu, Pierre. 1986. «The forms of capital.» In Handbook of Theory and Research for the Sociology of Education, ed. John G. Richardson, 241-58. New York: Greenwood Press.

Bröckling, Ulrich. 2007. Das unternehmerische Selbst: Soziologie einer Subjektivierungsform. Frankfurt a.M.: Suhrkamp.

Brown, Phillip and Hugh Lauder. 2006. "The knowledge economy, knowledge capitalism, creativity and globalization.» In Education, globalization, and social change, ed. Hugh Lauder, Phillip Brown, Jo-Anne Dillabough and Albert Henry Halsey, 117-137. Oxford: Oxford University Press.

Butterwegge, Christoph, Bettina Löschand RalfPtak.2008. Kritikdes Neoliberalismus. 2., verbesserte Auflage. Wiesbaden: VS Verlag für Sozialwissenschaften.

Dourish, Paul. 2004. «What we talk about when we talk about context.»Personal and Ubiquitous Computing 8 (1): 19-30. http://www. dourish.com/publications/2004/ PUC2004-context.pdf. 
Ganguin, Sonja. 2008. «Medienökologie.» In Handbuch Medienpädagogik, ed. Uwe Sander, Friederike von Gross and Kai-Uwe Hugger, 136-141. Wiesbaden: VS Verlag für Sozialwissenschaften.

Ganguin, Sonja and Uwe Sander. 2005. «Medienökologie.» In Qualitative Medienforschung: Ein Handbuch, ed. Lothar Mikos and Claudia Wegener, 130-140. UVK Verlagsgesellschaft.

Gibson, James Jerome. 1979. The Ecological Approach to Visual Perception. Boston: Houghton Mifflin.

Gibson, Eleanor. J. and Anne D. Pick. 2000. An Ecological Approach to Perceptual Learning and Development. Cambridge: Oxford University Press.

Giddens, Anthony. 1984. The Constitution of Society: Outline of the theory of structuration. Cambridge: Polity Press.

Gonon, Philipp. 2008. Vom ehrbaren Handwerker zum innovativen SelfEntrepreneur. Modernisierung der Berufsbildung anhand idealtypischer Leitfiguren, ed. Bertelsmann Stiftung, Reihe Jugend und Arbeit, Positionen. Gütersloh: Bertelsmann Stiftung.

Horkheimer, Max and Theodor W. Adorno. 1944. "Kulturindustrie, Aufklärung als Massenbetrug.»In Dialektik der Aufklärung, ed. Max Horkheimer and Theodor W. Adorno, 128-176. Frankfurt: Fischer, 1969.

Humboldt, Wilhelm v. 2002. "Theorie der Bildung des Menschen. Bruchstücke.» In Wilhelm von Humboldt. Werke in fünf Bänden. Band I: Schriften zur Anthropologie und Geschichte, ed. Andreas Flitner and Klaus Giel, 234-240. 4. Aufl. Darmstadt: Wissenschaftliche Buchgesellschaft.

Kollar, Ingo and Frank Fischer. 2008. «Was ist eigentlich aus der neuen Lernkultur geworden? Ein Blick auf Instruktionsansätze mit Potenzial zur Veränderung kulturell geteilter Lehr- und Lernskripts.» Zeitschrift für Pädagogik 54 (1): 49-62.

Kress, Gunther. 2010. «Learning and environments of learning in conditions of provisionality.» In Medienbildung in neuen Kulturräumen. Die deutschsprachige und britische Diskussion, ed. Ben Bachmair, 171-182. Wiesbaden: VS Verlag für Sozialwissenschaften.

Lash, Scott, Anthony Giddens and Ulrich Beck. 1994. Reflexive modernization: Politics, tradition and aesthetics in the modern social order. Cambridge: Polity Press.

Lave, Jean and Etienne Wenger. 1991. Situated learning: Legitimate peripheral participation. Cambridge: Cambridge University Press.

Lauder, Hugh, Phillip Brown, Jo-Anne Dillabough, Albert Henry Halsey, Eds. 2006. Education, globalization, and social Change. Oxford: Oxford University Press.

Legg, Robert. 2012. "Bach, Beethoven, Bourdieu: «Cultural capital» and the scholastic canon in England's A-level examinations.» Curriculum Journal 23 (2): 157-172. 
Lehner, Franz. 2010. "Ökologie.»In Handbuch der Wissensgesellschaft. Theorien, Themen und Probleme, ed. Anina Engelhardt and Laura Kajetzke, 271-280. Bielefeld: transcript.

McCrone, Tami, Clare Southcott, Gill Featherstone, Shona Macleod and Anneka Dawson 2013. «Research into Training for Young Adults Aged 19 to 24 Who are Not in Education, Employment or Training (NEET)» BIS Research Papers, Number 95. London: Department for Business, Innovation and Skills. https:// www.gov.uk/government/uploads/system/uploads/attachment_data/ file/70279/bis-13-609-research-into-training-for-young-adults-aged-19-to24-who-are-not-in-education-employment-or-training-NEET.pdf. Website: Department for Business, Innovation and Skills (BIS).

Oliver, Martin. 2005. «The problem with affordance.» E-Leaning 2 (4): 402-413.

Pachler, Norbert, Ben Bachmair and John Cook. 2010. Mobile Learning: Structures, agency, practices. New York: Springer.

Pachler, Norbert, John Cook and Ben Bachmair. 2010. «Appropriation of mobile cultural resources for learning.» International Journal for Mobile and Blended Learning 2 (1): 1-21.

Postman, Neil. 1983. Das Verschwinden der Kindheit. Frankfurt a.M.: S. Fischer. English Original (1982): The Disappearance of Childhood. New York: Delacorte Press.

Postman, Neil. 1993. Wir amüsieren uns zu Tode: Urteilsbildung im Zeitalter der Unterhaltungsindustrie. Frankfurt a.M.: S. Fischer. (Erste deutsche Ausgabe: 1985. English Original: Amusing Ourselves to Death: Public Discourse in the Age of Show Business. New York: Penguin Books.)

Rymes, Betsy R. 2011. «Deference, denial, and beyond. A repertoire approach to mass media and schooling.» Review of Research in Education 35 (1): 208-238.

Scardamalia, Marlene and Carl Bereiter. 1999. "Schools as knowledge-building organizations.» In Today's children, tomorrow's society: the developmental health and wealth of nations, ed. Daniel P. Keating and Clyde Hertzman, 274289. New York: Guilford.

Wortham, Stanton. 2011. "Youth Cultures and Education.» Review of Research in Education 35 (1): vii-xi. 